Volumen XXI, número 2,

Julio-diciembre de 2021.

Recibido: 30 de octubre de 2019.

Revista de Estudios

Transfronterizos

Aprobado: 30 de julio de 2021.

\title{
Del Sumak Kawsay al debate por el Buen Vivir: significados en disputa y disputa por los significantes*
}

\section{From Sumak Kawsay to Living Well debate: Signified in dispute and dispute for signifiers}

\author{
Juan Pablo Vásquez Bustamante ${ }^{* *}$ \\ Universidad Miguel de Cervantes, Chile
}

\author{
José Orellana Yáñez ${ }^{* * *}$ \\ Escuela de Ciencia Política y Relaciones Internacionales, \\ Universidad Academia Humanismo Cristiano, Chile
}

\author{
Juliane Rodrigues Teixeira ${ }^{* * * *}$ \\ FLACSO, Ecuador
}

\begin{abstract}
* Este artículo es producto del proyecto FONDECYT N 1190481: “América Latina en la geopolítica ambiental pos-Guerra Fría de los Estados Unidos. Antecedentes históricos y proyecciones (1989-2017)”.

${ }_{* *}$ Doctor (c) en Estudios Americanos, Instituto de Estudios Avanzados, Universidad de Santiago de Chile (IDEA-USACH). Profesor, Universidad Miguel de Cervantes. Correo electrónico: juan.vasquez@profe.umc.cl ORCID: 0000-0001-7449-4769.

${ }^{* * *}$ Doctor en Estudios Americanos, Instituto de Estudios Avanzados, Universidad de Santiago de Chile (IDEAUSACH), magíster en Ciencia Política, Universidad de Chile. Licenciado en Geografía y geógrafo, Pontificia Universidad Católica de Chile. Académico de la Escuela de Ciencia Política y Relaciones Internacionales, Universidad Academia Humanismo Cristiano. Correo electrónico: jorellanay@gmail.com ORCID: 00000002-6342-7664.

${ }^{* * * *}$ Doctora (c) en Estudios Americanos, Instituto de Estudios Avanzados, Universidad de Santiago de Chile (IDEA-USACH. Magíster en Estudios Internacionales y licenciada en Derecho (PUCRS, Brasil). Investigadora visitante, FLACSO Ecuador. Correo electrónico: juliane.rt@gmail.com ORCID: 0000-0002-8995-2619.
\end{abstract}

Cómo citar este artículo: Vásquez, J., Orellana, J. y Rodrigues, J. (2021). Del Sumak Kawsay al debate por el Buen Vivir: significados en disputa y disputa por los significantes. Si Somos Americanos. Revista de Estudios Transfronterizos, 21(2), 120-145. doi: 10.4067/S0719-09482021000200120 


\title{
Resumen
}

El término "Buen Vivir" ha sido planteado como la traducción al castellano del principio filosófico kichwa-amazónico del Sumak Kawsay. A partir de su incorporación en la Constitución de la República del Ecuador en 2008 como modelo de sociedad y horizonte de realidad, se ha generado un intenso debate político y académico entre distintas formas de entender e interpretar este concepto. Este artículo concibe el Buen Vivir como un significante, objeto de una permanente disputa por su significación y apropiación. A través de un análisis documental de fuentes primarias y secundarias, y sobre la base de un trabajo de análisis y síntesis de tres propuestas de tipologías para estos debates, este artículo analiza y reordena el campo de tensión (o discusión) en cuatro corrientes o grupos de discursos que, a partir de sus intereses, perspectivas y marcos paradigmáticos, arguyen sobre la significación y apropiación del ideal del Buen Vivir.

Palabras claves: Sumak Kawsay/Buen vivir, Ecuador, desarrollo.

\begin{abstract}
The Buen Vivir (Living Well) notion has been set out as the Amazonic Kichwa philosophical principle's representation in Spanish for Sumak Kawsay. From its incorporation to the Constitution of the Republic of Ecuador as a model of society and reality horizon, this concept has generated an intense political and academic debate between different ways of interpretation and understanding. According to this problem phenomenon, this paper sets out Living Well as a signifier, which is a permanent-disputing political object because of its significance and appropriation. A documentary analysis of primary and secondary sources, and an analysis and synthesis work to three proposals for typologies that fit these debates are carried out. This work analyzes and arranges the field in dispute into four discourse currents or groups that -according to its interests, perspectives and paradigmatic frames- dispute the Living Well significance and appropriation.
\end{abstract}

Keywords: Sumak Kawsay/Living Well, Ecuador, development.

\section{Introducción}

Las nociones de Buen Vivir y Vivir Bien han sido planteadas como traducciones o representaciones al castellano de los principios filosóficos Sumak Kawsay y Suma Qamaña, provenientes de las tradiciones amazónica kichwa y andina aymara, respectivamente, asociadas a prácticas sociales, saberes ancestrales y formas de comprender la realidad de estos pueblos. Ambos pueden entenderse como "vida plena" o "vida en plenitud", y describen un conjunto de relaciones que expresan una forma de vida limpia y plena entre los seres 
humanos y la naturaleza, equivalente a un todo armónico y equilibrado (Huanacuni, 2010; Viteri, 2003).

Dichos conceptos han sido incorporados al debate público y político en Ecuador y Bolivia, e institucionalizados a nivel estatal a través de su reconocimiento y proclamación como horizonte de realidad y modelo de sociedad en la Constitución y en los documentos de planificación económica y productiva (Asamblea Constituyente de Bolivia, 2009; Asamblea Constituyente del Ecuador [ACE], 2008a; Ministerio de Planificación del Desarrollo, 2016; Secretaría Nacional de Planificación y Desarrollo [SENPLADES], 2009; SENPLADES, 2013).

Lo anterior da cuenta de la introducción de ambos conceptos en el centro del debate político durante las dos primeras décadas del siglo XXI, incidiendo en la formulación de políticas públicas, como fruto de una hibridación de la sabiduría de los intelectuales y dirigentes del movimiento indígena, quienes se mueven tanto dentro del paradigma epistemológico y cultural occidental como del indígena, difundiendo sus planteamientos como alternativas al modelo de desarrollo hegemónico (Hidalgo-Capitán, Guillén y Deleg, 2014). De esta forma, una de las oportunidades que ha brindado la emergencia, consolidación y proyección del movimiento indígena es la cosmovisión que particulariza a los pueblos ancestrales y que él mismo ha articulado como propuesta filosófica y política, tanto en Ecuador como en Bolivia.

Existe coincidencia entre académicos respecto a que los debates en torno al Buen Vivir pueden organizarse en tres corrientes. Vanhulst (2015) ordena las aproximaciones a ambas nociones en tres grupos: el socialista, el posestructuralista y el indigenista. Le Quang y Vercoutère (2015) plantean una corriente ecomarxista, otra ecologista y una tercera, culturalista, mientras que para Hidalgo-Capitán y Cubillo-Guevara (2014) se trataría de una tendencia socialista o estatista, una ecologista y posdesarrollista, y una tercera, indigenista o pachamamista.

Estas tipologías aportan elementos para contestar los siguientes cuestionamientos: ¿qué es el Buen Vivir?, ¿qué significan Buen Vivir y Vivir Bien?, ¿cuál es el grado de fidelidad que guardan con sus acepciones madres de Sumak Kawsay y Sumak Qamaña?, ¿cómo se organizan estos enfoques filosóficos?

Para Le Quang y Vercoutère (2015), el Buen Vivir sería un concepto en disputa política y, por tanto, en construcción. Asumiendo este planteamiento, se propone acá al término "Buen Vivir" como un significante en disputa, en el que cada una de las corrientes anteriormente señaladas en este debate, más que yuxtapuestas u antagónicas, forman parte de una tensión y un permanente proceso de apropiación, significación y resignificación del ideal del Buen Vivir. $^{1}$

\footnotetext{
${ }^{1}$ La noción de significante y su relación con el significado es desarrollada por distintos autores, como Michel Foucault (1996) o Ernesto Laclau (2016); sin embargo, en este trabajo se utilizan los planteamientos realizados por el lingüista suizo Ferdinand de Saussure (2012). Para este, el signo lingüístico se compone de dos partes: el
} 
En este marco, es aquel proceso de disputa el campo donde se construye políticamente el significado del Buen Vivir, así como la fuente donde encontrar los elementos y claves que permitan entenderlo. Esto es importante en la medida en que es esencial identificar las propuestas políticas que se encuentran detrás de los distintos significados de este concepto, evidenciando las disputas en torno a su definición (Cubillo-Guevara, 2016).

Este artículo busca profundizar críticamente en las tipologías que dan cuenta del enfoque/cosmovisión/filosofía/política del Buen Vivir. Como objetivos específicos, se tienen: a) presentar una reorganización de la discusión tras la revisión crítica de las tipologías enunciadas; b) proponer una tipología o clasificación del Buen Vivir que emerge tras el análisis crítico de las anteriores, evidenciando una nueva tendencia en disputa; y finalmente, c) lograr una síntesis analítica de esta reorganización de tipologías, junto con exponer las nuevas propuestas tipológicas.

Metodológicamente, se enfoca en el Sumak Kawsay y el Buen Vivir, vinculados con la experiencia ecuatoriana, y toma el Suma Qamaña, asociado a la experiencia boliviana, solamente como una referencia cuando aquello sea requerido y señalado. Así, el texto se centra en el análisis teórico-filosófico-político e institucional ecuatoriano en cuanto proviene de una línea de investigación trabajada por los autores, en la que los conflictos y transformaciones políticas desarrolladas en Ecuador en las primeras décadas del siglo XXI en relación con el modelo de desarrollo, la geopolítica ambiental y los recursos naturales, ocupan un lugar fundamental (Estenssoro y Vásquez, 2017, 2018; Ramos y Vásquez, 2018; Vásquez, 2015; Vásquez y Clavería, 2020).

En este caso, Ecuador incorpora el Buen Vivir explícitamente en su ordenamiento constitucional en la temporalidad analizada, como también en el diseño, ejecución y planificación de políticas públicas para el desarrollo, abordadas algunas de ellas en apartados siguientes. A partir de esto, se utilizó el neoinstitucionalismo sociopolítico (Mondol, 2018), en cuanto el objeto investigado es la síntesis entre la operatividad del movimiento indígena y la institucionalidad estatal, plasmado tanto en la Constitución Política del Estado como en el diseño de política pública tendiente a un nuevo enfoque de desarrollo, cuestión que se describe en el cuerpo del artículo.

significado y el significante. En este marco, el significante es la parte sensorial que puede percibirse con los sentidos: la secuencia de sonidos o representaciones gráficas, es decir, lo que se oye al hablar y/o lo que se ve al escribir o leer. En el caso del objeto de estudio de este trabajo, el significante es el vocablo gráfico Buen Vivir. Por su parte, el significado es la imagen acústica que se asocia mentalmente al significante. En el caso de este trabajo, el significado es la noción o idea evocada en la mente al utilizar el significante Buen Vivir. Para Saussure, el significado es "arbitrario" (p. 144), es decir, no hay una conexión interna e intrínseca en el signo lingüístico entre significado y significante; más bien, se trata de una asociación de naturaleza social. En el caso del objeto de estudio de este trabajo, este punto es esencial, pues al tratarse de un concepto y/o signo lingüístico de relevancia y fuerte controversia, ese espacio de asociación arbitraria y de naturaleza social se constituye en un campo de disputa política, donde en el que distintos actores buscan llenar de un significado en particular el significante Buen Vivir. 
Las técnicas metodológicas utilizadas fueron: a) revisión de fuentes primarias, principalmente documentación oficial del Estado ecuatoriano; b) textos de intelectuales directamente involucrados en la conceptualización y la difusión de la noción del Buen Vivir a la luz del proceso consignado, desplegándose los mismos en el desarrollo del artículo; c) revisión y estudio de fuentes secundarias, analizando algunos de los principales artículos académicos que abordan los debates sobre el Buen Vivir de acuerdo con las tipologías tratadas.

El artículo se divide en cuatro partes: primeramente, se intenta responder las preguntas qué es y de dónde surge el Sumak Kawsay; en segundo lugar, a partir de las tipologías ya propuestas por otros autores, se analizan los discursos en torno al Buen Vivir; en tercer lugar, se proponen nuevas corrientes en disputa a partir de las tensiones diagnosticadas en las clasificaciones tradicionales; en cuarto lugar, se abordan distintas reflexiones sobre conceptos que ayudan a visibilizar los contrastes y las tensiones existentes entre estas corrientes; y finalmente, se establecen algunas conclusiones y reflexiones.

\section{¿Qué es el Sumak Kawsay?}

Desde los pueblos indígenas, el Sumak Kawsay es comprendido como una filosofía de vida en armonía con la naturaleza y su dimensión espiritual. Dicho concepto ha sido planteado como un principio filosófico originario de los sarayakuruna, pueblo kichwa de Sarayaku, provincia de Pastaza, ubicada en la región amazónica del Ecuador. Forma parte de su filosofía, ciencia, cosmovisión o conjunto de saberes ancestrales y formas de entender la realidad (Viteri et al. cit en Silva, 2003; Viteri, 1993, 2003).

Para el antropólogo kichwa de Sarayaku, Carlos Viteri Gualinga (2003), el Sumak Kawsay se constituye como una filosofía de vida fundada en un sistema de relaciones sociales, políticas, económicas, ambientales y espirituales, lo que los sarayakuruna conciben como "el sentido ideal de la vida"; una condición de existencia sin carencias o crisis; una situación de vida armónica, deseable e ideal, íntimamente asociada a un componente espacial (territorio) y a un orden moral, ético y espiritual, en cuya base interactúan individuos, sociedades y los seres del ambiente. Esta noción orientaría el modo de vida, regulando las relaciones entre seres humanos sobre la base de principios igualitarios, comunitarios y recíprocos, y se alimentaría del diálogo con la naturaleza y su dimensión espiritual (Viteri et al. cit. en Silva, 2003).

Por su parte, Hidalgo-Capitán, Guillén y Deleg (2014) apuntan al concepto como práctica social de los grupos indígenas, señalando que algunos intelectuales indigenistas lo han estado recreando a partir de instituciones ancestrales que persisten en la actualidad, vinculando esta noción con prácticas sociales y comunitarias. Gran parte del pensamiento sobre el Sumak Kawsay es transmitido de forma oral en el interior de estos grupos, tornando necesario la existencia de un puente entre el conocimiento ancestral y el mundo académico occidental, 
desarrollado mayormente por los intelectuales indígenas ${ }^{2}$ que han propiciado los debates en torno a este concepto.

Para Viteri (2003), al buscar una forma de representación al castellano, Sumak Kawsay expresa el ideal del "Buen Vivir" o "vida armónica" de los kichwas de Sarayaku. Se trata de "un concepto formado por dos palabras: Sumak: lo bueno, lo bello, lo armónico, lo perfecto, lo ideal, y Kausai: vida, existencia" (p. 46). Para Fernando Huanacuni (2010), filósofo aymara boliviano, Sumak puede traducirse al castellano como plenitud, sublime, excelente, magnífico, hermoso(a), superior, y Kawsay, como vida, ser estando, estar siendo. Desde su óptica, la expresión "vida en plenitud" sería la traducción que más se aproxima tanto a Sumak Kawsay como a Suma Qamaña (2010, p. 13).

Hidalgo-Capitán, Guillén y Deleg (2014) apuntan a la importancia de la redacción de la Constitución de Montecristi, ${ }^{3}$ a través de un proceso participativo que incluyó el movimiento indígena y otros movimientos sociales, introduciendo el concepto de "Buen Vivir en armonía con la naturaleza" como referencia al Sumak Kawsay. De esta forma, en la elaboración de este documento participaron actores políticos, organismos y/o individuos vinculados a los debates en torno al Sumak Kawsay, influenciando o siendo directamente los responsables por las menciones al "Buen Vivir" en "armonía con la naturaleza", y, por lo tanto, responsables de partes de los contenidos y de las ideas que componen el significante "Buen Vivir".

La consolidación de este hito puede considerarse un punto de llegada de un proceso que venía desde inicios de los años noventa del siglo pasado. ${ }^{4}$ Sin embargo, también puede plantearse como un punto de partida, pues abrió una etapa de intenso debate político y académico en su entorno. Es así como, desde los años 2007 y 2008, aumenta el número de citas y publicaciones científicas respecto a este concepto, adquiriendo "cierta importancia internacional" (Vanhulst, 2015, p. 3) y sirviendo como inspiración a una serie de

\footnotetext{
${ }^{2}$ Carlos Viteri Gualinga es uno de los primeros intelectuales que ha sistematizado el concepto de Sumak Kawsay como alternativa al desarrollo, a partir del análisis de la realidad social de los pueblos amazónicos de Ecuador, transformando este fenómeno social en objeto del conocimiento científico occidental. De esta forma, Viteri puede ser considerado uno de los responsables de elaborar las conexiones entre los conocimientos ancestrales y científicos modernos (Hidalgo-Capitán y Cubillo-Guevara, 2014).

${ }^{3}$ La incorporación del Sumak Kawsay y Buen Vivir en los debates, informes y propuestas surgidas en la mesa constituyente $\mathrm{N}^{\mathrm{o}} 7$ "Régimen de Desarrollo" de la Asamblea Constituyente del Ecuador (ACE), y recogida por asambleístas de otras mesas constituyentes, como la $\mathrm{N}^{0} 5$, de Recursos naturales y biodiversidad, indican que sus propuestas se inscribían "en el nuevo modelo de desarrollo caracterizado como el 'buen vivir', el sumak kawsay, con un modelo viable, posible en las actuales condiciones históricas concretas del país, alternativo al modelo de desarrollo que hizo crisis y que amparó la larga noche neoliberal" (ACE, 29 de abril de 2008, p. 61). ${ }^{4}$ En 1992 se publicó el primer documento escrito que hacía mención al Sumak Kawsay, titulado: "Plan Amazanga. Formas de manejo de los recursos naturales en los territorios indígenas de Pastaza, Ecuador" (Plan Amazanga), un texto de autoría colectiva, elaborado por un grupo de dirigentes e intelectuales kichwas y mestizos, liderados por Alfredo Viteri Gualinga, fundador y líder histórico de la Organización de Pueblos Indígenas de Pastaza (OPIP), "cuya novedad es que por primera vez se expone el marco filosófico-conceptual kichwa-amazónico del manejo de los recursos" (Silva, 2003, p. 46). En dicho escrito plantean una concepción filosófica basada en tres principios: el Sumak Allpa, la tierra prodigiosa y sin mal, el Sacha Kausai Riksina, el arte de entender, comprender, conocer, y el Sumak Kawsai, representado al castellano en este documento como: "vida límpida y armónica" (Viteri et al. cit. en Silva, 2003, p. 85).
} 
movimientos sociales y sectores de izquierda europea (Le Quang y Vercoutère, 2015), generando, según Vanhulst (2015), una "red de actores trasnacionales" en articulación de "un proyecto alternativo que intenta apartarse del paradigma dominante del desarrollo y acercarse a un nuevo horizonte: el del "Buen vivir" (2015, p. 1).

\section{Los debates en torno al Buen Vivir. ¿Tres corrientes en disputa?}

El concepto del Buen Vivir ha logrado penetrar en circuitos de la intelectualidad y de la dirigencia política no indígena de izquierda a través del trabajo y la influencia de personalidades y actores que participaron en los debates y en su difusión. Sin embargo, las discusiones sobre el Buen Vivir no giran en torno a un paradigma unívocamente definido y estático. Los diversos actores se enfrentan a partir de sus propias visiones respecto al mismo, respondiendo de distintas maneras a la pregunta ¿qué es el Buen Vivir? La incorporación del Sumak Kawsay en la Constitución ecuatoriana transformó este concepto en permanente objeto de debate y disputa en torno a su significado y su apropiación.

Las aproximaciones al Buen Vivir planteadas por Vanhulst (2015) (indigenista, posestructuralista y socialista), por Le Quang y Vercoutère (2015) (culturalista, ecologista y ecomarxista), y por Hidalgo-Capitán y Cubillo-Guevara (2014) (indigenista y pachamamista, ecologista y posdesarrollista, y socialista o estatista), mencionadas anteriormente, nos hablan de tipologías que parecen ser asimilables, pudiéndose desarrollar un ejercicio de síntesis que permitiría efectivamente identificar tres corrientes.

\section{Corriente indigenista ${ }^{5}$}

La tendencia indigenista planteada por Vanhulst, la culturalista de Vercoutère y Le Quang, y la indigenista y pachamamista de Hidalgo-Capitán y Cubillo-Guevara, podrían confluir en una corriente principalmente definida y caracterizada por establecer una relación estrecha y

\footnotetext{
${ }^{5}$ Es preciso consignar que tanto Vanhulst (2015) como Hidalgo-Capitán y Cubillo-Guevara (2014) utilizan el término indigenista para referirse a la corriente del Buen Vivir que vincula más estrecha y directamente este concepto con la tradición y cosmovisión de los pueblos indígenas, incluyendo en ella a dirigentes e intelectuales del mundo indígena. A partir de aquello, este artículo ocupa el término indigenista asociado a las ideas y debates generados por intelectuales indígenas y no indígenas, a propósito de la flexibilidad analítica que permite. Sin embargo, la literatura especializada se refiere al término indigenista como un proceso de asimilación desde los Estados, que toman a los indígenas como a un objeto. En este sentido, Devés-Valdés (2014) se refiere al indigenismo e indianismo, señalando: "los Estados latinoamericanos decidieron construir la identidad mestiza de las sociedades nacionales a través de políticas indigenistas que subordinaban las identidades indígenas, negras y otras en la identidad única, nacional y el indianismo fue generado por líderes, pensadores y organizaciones indígenas [...] que plantean proyectos ideológicos, políticos y culturales que reivindican el protagonismo de los pueblos indígenas en pugna con el pensamiento y cultura occidental. [...] Este indianismo alegó el carácter occidental de la democracia y denunció la naturaleza explotadora, etnocéntrica y racista a los pueblos de raíz occidental, contrapuesto a las virtudes de los pueblos indios dentro de una concepción esencialista étnica" (p. 620).
} 
directa del Buen Vivir con el Sumak Kawsay como tradición de los pueblos indígenas, buscando la construcción de una versión más pura y prístina del concepto.

Se caracteriza por la centralidad dada a la autodeterminación, a través de la plurinacionalidad y la interculturalidad, y la referencialidad atribuida a las cosmovisiones de los pueblos indígenas (Hidalgo-Capitán y Cubillo-Guevara, 2014; Vanhulst, 2015). Propone una alternativa al desarrollo al rechazar la modernidad como el marco de referencia cultural, introduciendo el paradigma andino y amazónico. Por ende, contribuye a la formación del discurso político de los movimientos indígenas del continente, ${ }^{6}$ especialmente de Ecuador y Bolivia, ${ }^{7}$ originando políticas de resistencia y alternativas al capitalismo y a la modernidad:

La cosmovisión occidental, de la que deriva la modernidad como marco cultural de referencia. Modernidad que se concreta en el Estado-nación, el capitalismo, el racionalismo y la democracia. El Estado-nación terminó generando el colonialismo sobre los pueblos indígenas. El capitalismo propició la aplicación de políticas neoliberales que permitieron la inserción nacional en el mercado mundial, generando con ello un proceso de crecimiento económico, que a su vez es fundamento del modelo de desarrollo económico denominado extractivismo, basado en la extracción de recursos naturales. El racionalismo, por su parte, aplicado a otras culturas, generó violencia epistemológica, la cual terminó propiciando la invisibilización ontológica de los pueblos indígenas. [...] Todos estos elementos, colonialismo, extractivismo, invisibilización ontológica terminaron generando la marginación de una parte de la sociedad nacional, en particular de los pueblos indígenas e innumerables conflictos que desembocaron en la crisis de la modernidad (Cubillo-Guevara, Hidalgo-Capitán y Domínguez-Goméz, 2014, p. 42).

En esta tendencia se incluirían los "discursos que se articulan en torno a la afirmación de la filiación del concepto de Sumak Kawsay a las culturas de los pueblos indígenas del Abya Yala $^{8}$ en general y a las culturas de los pueblos andinos en particular" (Le Quang y

\footnotetext{
${ }^{6}$ Los movimientos indígenas apoyan la ruptura con el pensamiento dominante y monocultural, criticando el colonialismo; cuestionando el modelo neoliberal, el Estado oligárquico y la dependencia al entorno regional, así como la inestabilidad política y el deterioro económico generado durante la década de 1990. Además, el pensamiento de los pueblos indígenas se condice con el debate crítico sobre el desarrollo, puesto que en su cosmovisión no existe el concepto de desarrollo como un proceso lineal que establezca un estado anterior y otro posterior, como el subdesarrollo y el desarrollo (Hidalgo Flor, 2011, pp. 87-89).

${ }^{7}$ Esta corriente ejerció gran influencia en la elaboración de la Constitución boliviana, y simboliza un hito importante de refundación del país, apoyado en el reconocimiento de la pluralidad cultural y étnica, al buscar también recuperar la memoria de los grupos ancestrales y generar influencias tanto en la elaboración de las políticas internas, como en la política exterior. De este modo, contribuyó a la llegada al poder del primer presidente indígena y a propiciar los consecuentes cambios políticos y sociales en el país que culminaron con la Constitución de 2009. Así, "se trata pues de un hito importante que simboliza la refundación del país, se sustituye la República por el Estado Plurinacional, lo que apunta a ir más allá del reconocimiento de la pluralidad étnica y cultural, y recuperar la memoria ancestral de los pueblos, acallada durante quinientos años de colonia y República" (Querejazu Escobari, 2015, p. 164).

${ }^{8}$ Según Walsh (2008), se refiere al "término acuñado por los pueblos kuna de Panamá para referir a los pueblos indígenas de las Américas que traduce como 'tierra en plena madurez'. [...] Esta forma de nombrar tiene un doble significado: un posicionamiento político y un lugar de enunciación. Es decir, una forma de enfrentar el
} 
Vercoutère, 2015, p. 21) (2015, p. 21). Para Le Quang y Vercoutère (2015), esta exaltación de las raíces indígenas con frecuencia se acompaña de una afirmación de estos pueblos como detentores legítimos de saberes y conocimientos ancestrales.

En este marco, se destaca la importancia del movimiento indígena ecuatoriano, dado que la defensa del Sumak Kawsay agrupa reivindicaciones tradicionales, como el Estado plurinacional, la autodeterminación de los pueblos, el respeto a las costumbres y organizaciones comunitarias de la sociedad, y su asociación con otros movimientos sociales, como el ambientalista, con el cual posee en común la defensa de la naturaleza y la propuesta de alternativas al tradicional desarrollo capitalista neoliberal (Hidalgo-Capitán, Guillén y Deleg, 2014). Así, en esta clasificación se inscribiría a intelectuales, dirigentes y líderes indígenas, así como a intelectuales indigenistas blancos y mestizos, tales como Carlos Viteri, Nina Pacari, Luis Macas, Blanca Chancoso, Floresmilo Simbaña, Pablo Dávalos, Javier Lajo o Xavier Albó (Hidalgo-Capitán y Cubillo-Guevara, 2014; Le Quang y Vercoutère, 2015).

\section{Corriente ecologista posestructuralista y posdesarrollista}

Las corrientes ecologista y posestructuralista de Le Quang y Vercoutère, la ecologista y posdesarrollista de Hidalgo-Capitán y Cubillo-Guevara, y la posestructuralista de Vanhulst, pueden ser sintetizadas en una segunda tendencia caracterizada por la búsqueda y exaltación de una relación armónica y equilibrada entre los seres humanos y la naturaleza, planteando el Buen Vivir como una noción biocéntrica.

Tal noción toma el Buen Vivir, lo interpreta, lo resignifica, lo llena de contenido y lo transforma en una alternativa epistemológica y paradigmática frente a la modernidad eurocéntrica, fundamentada en la importancia atribuida a la preservación de la naturaleza y la construcción participativa del concepto a partir de los aportes de distintos movimientos sociales, negando el desarrollo como camino único que debe ser seguido y alcanzado por todas las naciones, rechazando los metarrelatos y las verdades consideradas universales. Por ende, esta tendencia caracteriza el ideal del Buen Vivir como un "collage posmoderno de concepciones indígenas, campesinas, sindicalistas, cooperativistas, solidarias, feministas, pacifistas, ecologistas, socialistas, teólogo-liberacionistas, des colonialistas, etc." (HidalgoCapitán y Cubillo-Guevara, 2014, p. 28). Se advierte su vinculación con el pensamiento constructivista posmoderno, representado por intelectuales progresistas y movimientos sociales que constituyen "un lugar donde se compartiría una crítica al desarrollo y donde se pensarían alternativas a este último" (Le Quang y Vercoutère, 2015, p. 29).

Puede identificarse principalmente a activistas e intelectuales latinoamericanos y europeos, asociados principalmente al ecologismo y a algunos movimientos sociales críticos a la noción del desarrollo y, particularmente, a las políticas extractivistas de los gobiernos de Rafael Correa y Evo Morales, tales como: José María Tortosa, Leonardo Boff, Arturo Escobar,

peso colonial presente en América Latina, cuyo nombre marca nada más que un proyecto cultural de occidentalización articulado ideológicamente en el mestizaje" (p. 139). 
Gustavo Esteva, Eduardo Gudynas, Alberto Acosta, Patricio Carpio, Magdalena León, Rafael Quintero, Diana Quirola, Aníbal Quijano, Miriam Lang, Raúl Prada, Maristela Svampa, Edgar Lander (Hidalgo-Capitán y Cubillo-Guevara, 2014; Vanhulst, 2015), o el Grupo Permanente de Trabajo sobre Alternativas al Desarrollo de la Fundación Rosa Luxemburgo.

Esta corriente presenta como uno de sus exponentes a Alberto Acosta, uno de los fundadores del movimiento Alianza País, ${ }^{9}$ 'que más tarde pasó a integrar la oposición al gobierno, fue presidente de la ACE de 2008 y uno de los principales responsables de la introducción del Buen Vivir como concepto constitucional. Acosta (2015) resalta los pensamientos occidentales que convergen con las concepciones indígenas frente a la inviabilidad de mantener el modelo de desarrollo hegemónico a nivel global, apuntando a la importancia de los planteamientos indígenas para la construcción de los "buenos vivires". Así, considera que la definición del Buen Vivir debe ser resultado de un proceso participativo, como concepto plural que se vincula con las especificidades propias de cada cultura, diversificando aún más su significado (Cubillo-Guevara, 2016).

\section{Corriente socialista-estatista}

La corriente socialista propuesta por Vanhulst, la ecomarxista planteada por Le Quang y Vercoutère, y la socialista o estatista expuesta por Hidalgo-Capitán y Cubillo-Guevara, comparten supuestos comunes que, sin desconocer el origen del Sumak Kawsay en la tradición de los pueblos indígenas, se constituyen a partir de un proceso de interpretación, resignificación y búsqueda de llenar de contenido el "ideal del Buen Vivir" con elementos de tradiciones occidentales.

Para Hidalgo-Capitán y Cubillo-Guevara (2014), esta corriente se caracteriza por la "relevancia que le da a la gestión política estatal del Sumak Kawsay, así como a los elementos relativos a la equidad social" (p. 27). Según Vanhulst (2015), esta tendencia plantea el Buen Vivir como una propuesta racional de desarrollo que prioriza las cuestiones de justicia y equidad social, considerando en segundo plano el imperativo de la sustentabilidad, y cuestiones culturales e identitarias.

Le Quang y Vercoutère (2015) consideran que la corriente ecomarxista, a diferencia de la ecologista y la culturalista, no focaliza sus críticas hacia el mundo occidental, sino que se plantea en oposición al sistema capitalista. Podría incluirse el "socialismo del Sumak Kawsay", de René Ramírez (2010), según el cual el Buen Vivir implica la lucha contra las desigualdades y una mejor distribución de la riqueza, respetando la naturaleza y sus ciclos de

\footnotetext{
${ }^{9}$ Alberto Acosta, quien ocupara un lugar de relevancia en los orígenes de Alianza País y en la construcción de su primer plan de gobierno durante el año 2006 (Harnecker, 2011), había trabajado por años junto a Carlos Viteri en torno al Sumak Kawsay, constituyéndose en uno de sus principales divulgadores e impulsores en el ámbito académico, tanto nacional como internacional (Cubillo-Guevara e Hidalgo-Capitán, 2015; CubilloGuevara, 2016).
} 
reproducción, sin embargo, primero satisfaciendo las necesidades materiales de la población (Le Quang y Vercoutère, 2015).

Esta tendencia entiende que el Sumak Kawsay trasciende los planteamientos indígenas, complementándolos con aportes neomarxistas tomados de propuestas y procesos como el "socialismo del siglo XXI", el "socialismo comunitario", la "Revolución Ciudadana" y la "Revolución Bolivariana"; la "economía social y solidaria" o las múltiples manifestaciones en torno a la "resistencia a la globalización" (Hidalgo-Capitán y Cubillo-Guevara, 2014).

Para Vanhulst (2015), los representantes de esta corriente hablan del "Socialismo del Buen Vivir" como una variante andina del socialismo, y coincide en la referencialidad teóricoconceptual que encontrarían en el neomarxismo. Sin embargo, el autor también resalta la institucionalización de sus discursos a través de la Revolución ciudadana en Ecuador, o del gobierno de Evo Morales en Bolivia, y las contradicciones que se generarían a partir de sus prácticas vinculadas a vertientes "(neo)-extractivistas" y "neodesarrollistas" (2015).

Hidalgo-Capitán y Cubillo-Guevara (2014) plantean que, entre los principales representantes de esta perspectiva, estarían intelectuales latinoamericanos y europeos neomarxistas, e intelectuales y políticos vinculados a los gobiernos de Ecuador y Bolivia, como José Luis Coraggio, Álvaro García Linera, Pedro Páez, Ricardo Patiño, François Houtart, René Ramírez, Marta Harnecker, Atilio Borón, Boaventura de Sousa Santos, Valter Pomar, y la SENPLADES del Ecuador. Podría agregarse a Michael Löwy, propuesto por Vanhulst (2015).

Uno de los principales exponentes e ideólogos de esta corriente del Buen Vivir, proveniente del gobierno ecuatoriano, es René Ramírez, ${ }^{10}$ quien

formula una propuesta política inspirada en el Socialismo del Siglo XXI. Bajo este marco de referencia, propone combinar elementos de economía comunitaria, economía ecológica, economía de mercado, economía social y solidaria, y economía de los ciudadanos para generar un proceso de construcción colectiva que contribuya a un pacto de convivencia. Dicho pacto de convivencia junto con la voluntad política del Estado (derivada del Socialismo del Siglo XX), contribuirá a la implementación del Buen Vivir; el cual permitirá la armonía con la naturaleza [...] el respecto a la diversidad; [...] la satisfacción de necesidades materiales. [...] Mientras que el respeto a la diversidad contribuirá a la conformación del Estado plurinacional. (Fernández, Pardo, y Salamanca, 2014, p. 44).

Bajo esta perspectiva, se destaca la construcción del significado del Buen Vivir como sinónimo de bienestar posneoliberal, concibiendo el desarrollo como un proceso integral que trasciende el crecimiento económico, buscando mejorar la vida de los ciudadanos y romper

\footnotetext{
${ }^{10}$ René Ramírez es considerado uno de los ideólogos del Buen Vivir gubernamental al redactar el Plan Nacional para el Buen Vivir (2009-2013), elaborando así la primera definición del concepto desde el Estado, vinculado a la satisfacción de las necesidades, la calidad de vida en paz y armonía con la naturaleza y con las diversas culturas humanas (Cubillo-Guevara, 2016).
} 
con el neoliberalismo. De hecho, Cubillo-Guevara (2016) considera que, en el ámbito constitucional ecuatoriano, los postulados de origen indígenas del Buen Vivir fueron marginados ante el predominio de los postulados socialistas posneoliberales.

En el cuadro $\mathrm{N}^{\mathrm{o}} 1$ se exponen esquemáticamente las tres propuestas de las tres corrientes del Buen Vivir recientemente descritas, permitiendo distinguir a cada una de ellas y a sus respectivos autores y autoras.

Cuadro $N^{\circ}$ 1: Corrientes en disputa por el Buen Vivir

\begin{tabular}{lccc}
\hline \multicolumn{1}{c}{ Autores } & & Propuestas de Corrientes \\
\hline Vanhulst (2015) & Indigenista & Posestructuralista & Socialista \\
\hline Le Quang y & Culturalista & Ecologista & Ecomarxista \\
Vercoutère (2015) & & & \\
\hline Hidalgo-Capitán y & Indigenista y & Ecologista y & Socialista o estatista \\
Cubillo-Guevara & pachamamista & posdesarrollista & \\
$(2014)$ & & & \\
\hline
\end{tabular}

Fuente: elaboración propia a partir de Vanhulst (2015), Le Quang y Vercoutère (2015), Hidalgo-Capitán y Cubillo-Guevara (2014).

\section{¿Hacia la formulación de nuevas corrientes en la disputa por el significado del Buen Vivir?}

Al observar con atención la confluencia de las corrientes socialista de Vanhulst (2015), ecomarxista de Le Quang y Vercoutère (2015) y socialista o estatista de Hidalgo-Capitán y Cubillo-Guevara (2014), descritas anteriormente y expuestas en el cuadro $\mathrm{N}^{\circ} 1$, es posible identificar tensiones que se mueven entre dos formas diferentes de interpretar y significar el ideal del Buen Vivir. Más que una corriente con dos polos podría considerarse como dos tendencias en sí mismas que permiten la formulación de otras corrientes. Por un lado, una vertiente que busca construir una síntesis entre elementos de la tradición socialista, el pensamiento marxista y el Sumak Kawsay. Se trataría de la construcción de un socialismo que reconoce la tradición de los pueblos originarios del continente, en oposición y alternativa al capitalismo. Esta corriente podría denominarse "socialismo del Sumak Kawsay" o "socialismo del Buen Vivir".

Por otra parte, a partir del ensamblaje y/o articulación entre una apelación discursiva y simbólica al Buen Vivir, y la planificación y ejecución de políticas públicas en función de objetivos más clásicos del desarrollo y el bienestar, puede identificarse otra corriente en disputa, de corte estatista y neodesarrollista, vinculada con la dinámica de apropiación y resignificación del ideal del Buen Vivir. Esta tendencia está asociada al contexto de una 
economía periférica como la ecuatoriana, a demandas y objetivos como el mejoramiento de la calidad de vida material, la superación de la pobreza, la construcción de infraestructuras sanitarias y viales, la generación de obras públicas, la incorporación de masas marginadas a los sectores formales del trabajo, y con ello a la economía y a un mayor consumo, como una especie de "neodesarrollismo del Buen Vivir".

\section{Primera corriente: socialismo del Sumak Kawsay}

Las propuestas de Ramírez (2010) que hablan de "socialismo del Sumak Kawsay o biosocialismo republicano", pueden establecerse dentro de esta corriente. Para este autor, "se trata de dejar atrás los principios de una sociedad liberal/utilitaria y conformar un biosocialismo (igualitarismo) republicano" (p. 61). Se incluyen sus miradas críticas respecto del marxismo clásico, que, según él, no logra ir más allá del modo de producción capitalista.

Para Marx solo tienen valor aquellos bienes y servicios que pueden comercializarse y en donde se genera plus valor producto del trabajo; en una nueva teoría se debe valorar la vida bien vivida que como hemos señalado en otras ocasiones implica la generación y disfrute de bienes relacionales en el marco de vivir una vida digna. (Ramírez, 2017, pp. 188-189).

Según Ramírez (2017), en una "teoría del valor del Buen Vivir", el orden social no podría estar únicamente en función de la relación trabajo-consumo; el trabajo no podría ser la única actividad generadora de valor, habría que construir un sistema en el que las unidades de valor sean diversas, pero valoradas socialmente en el marco de la reproducción de una vida digna, de una vida buena, del Buen Vivir. En este marco, Ramírez (2017) se pregunta: “¿por qué es más importante un minuto de trabajo a un minuto de participar en procesos de deliberación pública o de compartir con amigos?", y plantea que en el capitalismo la unidad de valor es el dinero, el cual ha servido como unidad de cuenta y medio de intercambio. Sin embargo, "en otras ocasiones, se ha propuesto que la vida (buena) medida a través del tiempo sea la unidad de valor que dispute el sentido hegemónico al dinero [...]” (p. 190).

El Sumak Kawsay implica tener tiempo libre para la contemplación y la emancipación, y podría sintetizarse como

la satisfacción de las necesidades, la consecución de una calidad de vida y muerte dignas, el amar y ser amado, y el florecimiento saludable de todos, en paz y armonía con la naturaleza, para la prolongación de las culturas humanas y de la biodiversidad. (Ramírez, 2010, p. 61).

Así este autor vincula el Buen Vivir con elementos como emancipación, libertad, oportunidades, capacidades, potencialidades y reciprocidad, alternando el discurso gubernamental sobre este concepto, para compatibilizarlo con el socialismo del siglo XXI y el socialismo comunitario andino, al cuestionar las desigualdades, exclusiones y discriminaciones presentes en el país (Cubillo-Guevara, 2016). 
Asimismo, determinados pasajes de los documentos de planificación económica y productiva del Plan Nacional para el Buen Vivir de Ecuador (PNBV) podrían incluirse en esta corriente. En su versión para el periodo 2009-2013, el PNBV propone un cambio paradigmático desde el desarrollo hacia el Buen Vivir (SENPLADES, 2009), al declarar la necesidad de avanzar a nuevas formas de producir, consumir y organizar la vida. Afirma que la Constitución persigue valores socialistas que ponen a la igualdad en el centro de la construcción de otra sociedad; y habla de "un nuevo socialismo democrático" (p. 131).

De igual forma, este documento plantea que el nuevo paradigma "significa pasar de una economía del egoísmo a una economía del altruismo-solidario", es decir, "que lo socialmente eficiente implica competir compartiendo, generando riqueza motivados por el interés particular, pero respetando criterios de solidaridad, reciprocidad y justicia social" 11 (SENPLADES, 2009, p. 40).

El PNBV 2013-2017 indica que "el horizonte político de la Revolución Ciudadana es el Socialismo del Buen Vivir", y que este "articula la lucha por la justicia social, la igualdad y la abolición de los privilegios, con la construcción de una sociedad que respete la diversidad y la naturaleza. En tal sociedad podremos desarrollar nuestras capacidades y vivir digna y libremente" (SENPLADES, 2013, p. 24). Ambos documentos presentan espacios, por lo menos como aspiración y construcción simbólica, donde convergen elementos neomarxistas y el Sumak Kawsay en la perspectiva de avanzar hacia un cambio paradigmático.

Este plan del Estado ecuatoriano destaca la redistribución de los beneficios del desarrollo a través de la justicia social, vinculando el Buen Vivir con la reducción de las desigualdades sociales, la eliminación de la discriminación y exclusión social, y con garantizar los derechos de la naturaleza, conforme los planteamientos de la Constitución ecuatoriana, según las cosmovisiones de los pueblos indígenas (Cubillo-Guevara, 2016).

\section{Segunda corriente: neodesarrollismo del Buen Vivir}

Una segunda corriente proveniente de la tensión al interior de la vertiente socialista del Buen Vivir puede ser denominada "neodesarrollismo del Buen Vivir". Esta tendencia se vincula con el modelo de desarrollo implementado en Ecuador durante la Revolución Ciudadana, en el cual, a partir del incremento de los roles del Estado en el contexto de una economía en expansión, y financiada principalmente por los recursos derivados de la actividad extractiva y los altos precios de los commodities, se implementó un conjunto de políticas públicas en función de objetivos derivados de la noción del desarrollo y del bienestar, en tensión con las demandas de los pueblos indígenas y la convivencia en armonía con la naturaleza. En este contexto, para Cubillo-Guevara (2016), en los discursos estatales el Buen Vivir pasó a ser

\footnotetext{
${ }^{11}$ Elementos como reciprocidad, complementariedad y justicia social forman parte de los principales principios provenientes del Sumak Kawsay, que recoge las cosmovisiones de los pueblos ancestrales.
} 
sinónimo de desarrollo, lo cual está expresado en determinados pasajes del documento PNBV:

En este momento tenemos una de las economías más prósperas de América Latina. No lo decimos nosotros, lo reconoce el mundo entero. Nuestro crecimiento favorece a los más pobres. Ese crecimiento se traduce en obras, en impulso a la producción, empleo y mejores ingresos. Lo hemos conseguido casi triplicando la recaudación tributaria, sin aumentar impuestos y cobrando a los que más tienen. (SENPLADES, 2013, p. 15).

Si bien este documento no plantea explícitamente que el crecimiento, el aumento de la producción, el empleo y mejores ingresos sean equivalentes al Buen Vivir, los está asociando al considerarlos como uno de los principales logros y claves del proceso que sostiene esta noción como su horizonte. De este modo, su orientación se vincula con argumentos keynesianos $^{12}$ :

La inversión pública es una variable clave para lograr el crecimiento económico, por cuatro razones de carácter coyuntural y estructural. En primer lugar, la inversión pública aumenta la demanda agregada de la economía y, mediante los multiplicadores fiscales keynesianos, impulsa el crecimiento en el corto plazo. En segundo lugar, la misma inversión pública aumenta la dotación de capital de una economía, con lo cual se amplía la frontera de posibilidades de producción y se logra mayor crecimiento económico. En tercer lugar, la inversión pública constituye bienes públicos que incrementan la productividad sistémica de la economía, genera inversión complementaria y, por tanto, aumenta el crecimiento. Además, la inversión pública busca garantizar derechos mediante la generación y fortalecimiento de capacidades humanas, cuyo corolario es la mejora del talento humano. (SENPLADES, 2013, p. $15)$.

En esta línea, Muñoz (2012), secretario nacional de planificación entre los años 2013 y 2015, planteaba que la "acumulación y distribución de la riqueza", la "equidad y capacidades" y la "transformación del Estado" eran "tres grandes principios rectores de la transformación estructural que está viviendo el Ecuador” (p. 19). Muñoz, al cierre del documento de evaluación institucional a los resultados del PNBV 2009-2013, establecía:

Es necesario reconocer que hemos acertado en la conducción de la economía; que el crecimiento económico ha sido "pro pobre"; que la inversión ha dinamizado el desarrollo; que la política fiscal ha sido adecuada; que mejoramos los indicadores de empleo; que disminuimos la pobreza y mejoramos la distribución y la equidad; que tenemos importantes tasas de cobertura de servicios y que hemos transformado el Estado, entre otras.

\footnotetext{
${ }^{12}$ Este documento destaca la actuación del Estado en la economía, a partir de la renegociación de los contratos petroleros, la auditoría a la deuda externa y la reorientación de aquellos dineros hacia la inversión pública "más grande de la historia", repatriando "más de USD 2000 millones para la producción”, y canalizándolos hacia obras como: "más escuelas, más hospitales, más carreteras" (SENPLADES, 2013, p. 15).
} 
Pero también es valioso reconocer que aún no transformamos la matriz productiva; que aún no logramos una revolución agraria; que mantenemos un serio problema de balanza comercial no petrolera; que no mejoramos la calidad de los servicios en la medida de lo que esperamos; y que afrontar los cambios culturales será una tarea fundamental para el proceso. (Muñoz, 2012, p. 25).

El Informe a la Nación 2007-2017, elaborado por SENPLADES (2017), ${ }^{13}$ que buscaba "registrar los indicadores más importantes de la gestión de Gobierno durante los diez años de la Revolución Ciudadana" (p. 7), reconoce el "Buen Vivir" como el nuevo paradigma de desarrollo en construcción (p. 21), y destaca como grandes logros, la recuperación del rol de la Planificación Nacional en la búsqueda del desarrollo; el crecimiento económico sostenido y su redistribución; la generación de empleos en combinación con la eliminación de la tercerización; el aumento de la productividad; la presencia del Estado en el sector petrolero; el desarrollo de proyectos hidroeléctricos que lograron cubrir más del $90 \%$ de la demanda energética nacional.

El propio Rafael Correa ha establecido planteamientos que pueden incluirse en esta corriente. Es así como durante el año 2013, en un discurso frente a nacionalidades y comunidades indígenas en los "Diálogos para el Buen Vivir", Correa afirmaba: "El Buen Vivir significa haber superado la pobreza. No es Buen Vivir cuando nuestros niños no tienen buenas escuelas, cuando no tenemos electricidad, cuando no tenemos agua potable" (Presidencia República del Ecuador, 30 de agosto de 2013, 40m35s). En aquella ocasión, el entonces presidente ecuatoriano se refería especialmente a obras del gobierno como las escuelas y comunidades "del Milenio", los nuevos hospitales, las obras de alcantarillado, la reducción de la pobreza en comunidades indígenas, la gratuidad de la educación, o el primer lugar regional de Ecuador en cuanto a tasa de estudiantes provenientes de pueblos indígenas cursando educación superior (Presidencia República del Ecuador, 30 de agosto de 2013, $40 \mathrm{~m} 35 \mathrm{~s})$.

En esta tendencia pueden circunscribirse referencias utilizadas por Correa en su pensamiento económico y en su labor de Gobierno, relativas a académicos y tomadores de decisiones que han apuntado a un camino al desarrollo que involucra una mayor intervención del Estado, proteccionismo y la promoción de la "industria infantil" en lugar del libre mercado (Correa, 2010).

Ambas corrientes, "socialismo del Sumak Kawsay" y "neodesarrollismo del Buen Vivir", convivieron en el proceso de la Revolución Ciudadana, y por tanto en sus políticas públicas, planteando visiones distintas respecto al Buen Vivir, buscando influir políticamente a través de ideas o de determinadas personalidades. Este fenómeno indica la existencia de una tensión

\footnotetext{
${ }^{13}$ Este documento destaca la planificación e implementación de políticas en la búsqueda de modificar la matriz productiva para pasar de una economía primario-exportadora a una economía basada en conocimiento y valor agregado, proceso que implicó un impulso manufacturero en el que se vieron beneficiados sectores como la petroquímica, la metalmecánica y el turismo (SENPLADES, 2017, pp. 111-112).
} 
al interior del proceso, en que ambas tendencias intentaron significar el Buen Vivir de acuerdo con sus perspectivas y, simultáneamente, buscaron significar la obra del Gobierno a partir de sus propias visiones del Buen Vivir.

Ante la planificación y ejecución de las políticas públicas, la entrada en funcionamiento de las centrales hidroeléctricas, o ante los planes de modificación de la matriz productiva, se agudiza la tensión en torno a las preguntas: ¿a qué Buen Vivir corresponde?, ¿a qué tipo de régimen se encaminó todo aquello?

Esta tensión está presente en la propia Constitución, la cual plantea que Ecuador decidió construir "una nueva forma de convivencia ciudadana, en diversidad y armonía con la naturaleza, para alcanzar el buen vivir, el Sumak Kawsay" (ACE, 2008, p. 15), y define el "régimen de desarrollo" como: "el conjunto organizado, sostenible y dinámico de los sistemas económicos, políticos, socio-culturales y ambientales, que garantizan la realización del buen vivir, del Sumak Kawsay" (ACE, 2008, p. 135), mientras, simultáneamente, postula como objetivo del sistema económico: "Incentivar la producción nacional, la productividad y competitividad sistémicas, la acumulación del conocimiento científico y tecnológico, la inserción estratégica en la economía mundial y las actividades productivas complementarias en la integración regional", estableciendo como propósitos: "garantizar la soberanía alimentaria y la soberanía energética, generar empleo y valor agregado” (ACE, 2008, p. 157). Asímismo, determinados artículos de la Constitución establecen disposiciones que implican un proceso de "industrialización acelerado", con una "sustitución selectiva de importaciones como principio orientador” (Arauz, 2015, pp. 230-23

En el cuadro $\mathrm{N}^{\mathrm{o}} 2$ se exponen esquemáticamente las corrientes planteadas por los autores antes señalados, y se incluye la propuesta propia de clasificación de corrientes del Buen Vivir.

Cuadro $N^{\circ}$ 2: Corrientes en disputa por el Buen Vivir más propuesta propia a partir de estas

\begin{tabular}{|c|c|c|c|}
\hline Autores & & Propuestas d & corrientes \\
\hline $\begin{array}{l}\text { Julien Vanhulst } \\
\text { (2015) }\end{array}$ & Indigenista & Posestructuralista & Socialista \\
\hline $\begin{array}{l}\text { Le Quang y } \\
\text { Vercoutère (2015) }\end{array}$ & Culturalista & Ecologista & Ecomarxista \\
\hline $\begin{array}{l}\text { Hidalgo-Capitán } \\
\text { y Cubillo- } \\
\text { Guevara (2014) }\end{array}$ & $\begin{array}{l}\text { Indigenista y } \\
\text { pachamamista }\end{array}$ & $\begin{array}{c}\text { Ecologista y } \\
\text { posdesarrollista }\end{array}$ & Socialista o estatista \\
\hline Propuesta propia & $\begin{array}{l}\text { Indígena e } \\
\text { indigenista }\end{array}$ & $\begin{array}{c}\text { Ecologista } \\
\text { posestructuralista } \\
\text { y posdesarrollista }\end{array}$ & $\begin{array}{cc}\text { Socialismo } & \text { Neodesarro- } \\
\text { del Sumak } & \text { llismo del Buen } \\
\text { Kawsay } & \text { vivir }\end{array}$ \\
\hline
\end{tabular}

Fuente: elaboración propia sobre la base de Le Quang y Vercoutère (2015), Hidalgo-Capitán y CubilloGuevara (2014) y Vanhulst (2015). 
A continuación, el cuadro $\mathrm{N}^{\mathrm{o}} 3$ expone esquemática y comparativamente las dos nuevas corrientes del Buen Vivir propuestas en este artículo, planteando las principales variables que las definen, explican y distinguen, los autores asociados a la misma y la visión de desarrollo o de horizonte político que proyecta.

Cuadro $N^{\circ}$ 3: Socialismo del Buen Vivir y neodesarrollismo del Buen Vivir. Aspectos principales de las nuevas corrientes propuestas

\begin{tabular}{lcc}
\hline & \multicolumn{2}{c}{ Socialismo del Buen Vivir } \\
& $\begin{array}{l}\text { Socialismo del Sumak } \\
\text { Kawsay }\end{array}$ & Neodesarrollismo del Buen Vivir \\
\hline $\begin{array}{l}\text { Búsqueda de síntesis entre } \\
\text { elementos de la tradición } \\
\text { central } \\
\text { socialista, marxista y el } \\
\text { pensamiento de los pueblos } \\
\text { originarios }\end{array}$ & $\begin{array}{c}\text { Desarrollo con justicia social, en los } \\
\text { términos occidentales }\end{array}$ \\
\hline $\begin{array}{l}\text { Autores, } \\
\text { fuentes, } \\
\text { representantes }\end{array}$ & $\begin{array}{c}\text { René Ramírez y Andrés } \\
\text { Revolución Ciudadana }\end{array}$ & Rafael Correa. Planes y políticas de \\
\hline $\begin{array}{l}\text { Visión respecto } \\
\text { de la } \\
\text { modernidad }\end{array}$ & $\begin{array}{c}\text { Alternativa a la modernidad } \\
\text { capitalista }\end{array}$ & Alternativa desde la modernidad \\
\hline $\begin{array}{l}\text { Visión respecto } \\
\text { al desarrollo }\end{array}$ & $\begin{array}{c}\text { Rechazo y planteamiento de } \\
\text { una alternativa al desarrollo } \\
\text { capitalista }\end{array}$ & Alternativa de desarrollo capitalista \\
\hline
\end{tabular}

Fuente: elaboración propia.

\section{Distintas visiones sobre modernidad, desarrollo y recursos naturales}

Es posible encontrar contrastes y tensiones entre estas corrientes a partir de la visión de cada una respecto a la modernidad, el concepto de desarrollo y la extracción de recursos naturales. Es importante señalar que la confluencia o síntesis aquí propuesta de la corriente indigenista de Vanhulst, culturalista de Le Quang y Vercoutère, e indigenista y pachamamista de Hidalgo-Capitán y Cubillo-Guevara, en este artículo se denomina indígena e indigenista. Esta 
denominación, responde a integrar las reflexiones teóricas, empíricas y filosóficas provenientes desde intelectuales y dirigentes indígenas e intelectuales blancos y mestizos.

Esta corriente busca resaltar la importancia del movimiento indígena y de sus intelectuales como sujetos autónomos en la construcción de sus propias narrativas, en contraposición a los proyectos indigenistas de integración y mestizaje elaborados por los Estados-naciones latinoamericanos durante el siglo XX. Está vinculada al pensamiento y la cosmovisión tradicional de los pueblos indígenas, estableciéndose en un marco cultural distinto al surgimiento de la modernidad en Occidente, por lo cual se les ha denominado como "premoderno" (Hidalgo-Capitán y Cubillo-Guevara, 2014, p. 29). Sin embargo, remitir a los pueblos indígenas a una premodernidad sería plantearlos dentro de la lógica del "progreso lineal" y, en tanto tal, reducirlos a las categorías de salvaje y civilización. Esta corriente no responde a una "premodernidad", sino al entendimiento de la modernidad como un otro.

La corriente ecologista y posestructuralista se basa en el "constructivismo posmoderno" (Hidalgo-Capitán y Cubillo-Guevara, 2014, p. 28), evidenciado por el rechazo a la modernidad y el reconocimiento al fracaso de la concepción lineal del progreso y el objetivo del desarrollo. Esta tendencia aspiraría a ser parte de una transformación civilizacional, en la que el Buen Vivir constituiría un horizonte construido a partir múltiples e híbridos aportes. Bajo esta perspectiva, como forma de reacción al paradigma universalista fundamentado en la concepción de las trayectorias de las sociedades como un proceso lineal y convergente hacia la formación de un modelo único de referencia universal, dominado por los principios positivistas, surgen paradigmas que toman en cuenta las trayectorias sociales distintas y divergentes. Este discurso del Buen Vivir es crítico frente a las ideologías del progreso, de la racionalización y del universalismo, propias de la modernidad europea, proponiendo alternativas que cuestionan la idea de desarrollo (Vanhulst y Beling, 2013).

Para la corriente del socialismo del Sumak Kawsay, el problema no es la modernidad, sino las relaciones sociales capitalistas que ocurren en su interior. Por eso, se plantea la búsqueda del socialismo como una síntesis de elementos de distintas tradiciones, en la que Occidente, la modernidad y los postulados ancestrales están presentes. Por su parte, el neodesarrollismo del Buen Vivir se erige desde la modernidad occidental, utilizando principalmente sus contenidos, y estableciendo una propuesta que podría ser crítica, pero que no busca constituirse en una alternativa a ella.

Respecto al concepto de desarrollo en cada una de estas corrientes, puede apreciarse una mirada similar a su visión manifiesta en torno a la modernidad. Como lo planteara Viteri (2003), el "concepto lineal y progresivo del Desarrollo" (p. ii) no existe en la cosmovisión de los pueblos kiwchas amazónicos. Bajo esta lógica, si la modernidad es considerada como un otro, el concepto de desarrollo sería el objetivo o estadio ideal de este otro. Sin embargo, a partir del reconocimiento a los procesos de yuxtaposición, convivencia y transculturación, muchas veces forzados, violentos y traumáticos, el Sumak Kawsay ha sido planteado como 
respuesta y/o alternativa a ese objetivo o estadio ideal de ese otro. Es decir, no es un otro que se desconozca, es un otro al que se le opone.

A su vez, la corriente ecologista y posestructuralista puede entenderse desde una perspectiva posdesarrollista, e inclusive, políticamente antidesarrollista. Para esta, el desarrollo ha fracasado, pues sus promesas no se han cumplido para los países del Sur, y su "búsqueda de desarrollo" se basa en una explotación desmedida de la naturaleza (Le Quang y Vercoutère, 2015). Esta tendencia esboza la necesidad de construir una alternativa al desarrollo, y esa alternativa sería el Buen Vivir, un ideal en permanente construcción a partir de muchos e híbridos aportes.

Según Acosta (cit. en Fernández, Pardo y Salamanca, 2014), inicialmente el Buen Vivir fue elaborado como un proyecto destinado a pensar fuera de los límites impuestos por la forma tradicional de desarrollo, abriendo la posibilidad para imaginar otros mundos, incluyendo los derechos de la naturaleza y la profundización de los derechos colectivos. Lo que se buscaba era discutir alternativas al neoliberalismo a través de las aproximaciones a las economías indígenas, con componentes de la economía comunitaria y fuera de la sobreexplotación capitalista, propugnando la participación de distintos movimientos sociales (Fernández, Pardo y Salamanca, 2014).

Acosta agrega los caminos para llegar a esa armonía en términos económicos, al proyectar la disolución de las políticas extractivistas y la transición hacia el posextractivismo, ya que el extractivismo es un modo de acumulación sustentado en la violencia contra las comunidades y contra la naturaleza. El Buen Vivir debe ser logrado a través de reformas estructurales y la implementación de políticas de redistribución de renta, riquezas y reforma agraria, en oposición a la concentración de los recursos económicos y de tierras en las manos de las elites nacionales (Fernández, Pardo y Salamanca, 2014).

La corriente del socialismo del Sumak Kawsay reconoce que "no se necesitan alternativas de desarrollo, sino alternativas al desarrollo", pero centra sus críticas, no sobre la modernidad occidental, sino sobre el capitalismo (Le Quang y Vercoutère, 2015, p. 39), buscando construir una alternativa al desarrollo capitalista, En contraste, la corriente del neodesarrollismo del Buen Vivir, con ciertos símbolos y elementos del concepto, intenta constituir una alternativa de desarrollo capitalista. La convivencia y tensión de estas dos corrientes en la Revolución Ciudadana y el Gobierno ecuatoriano podría encontrar una interpretación en las palabras de Ramírez (2010):

En el caso ecuatoriano, si pensamos en momentos históricos, podríamos especular que primero es necesario construir una sociedad posneoliberal - primera etapa que están intentando vivir algunos países de América Latina-, luego un capitalismo popular o socialismo de mercado y finalmente un bio-socialismo republicano (p. 61).

Respecto a la extracción y utilización de recursos naturales, la corriente ecologista y posestructuralista podría plantearse como antiextractivista, lo que los lleva a una permanente 
tensión y oposición con la corriente del socialismo del Sumak Kawsay y el neodesarrollismo del Buen Vivir. Para los ecologistas y posestructuralistas, si bien el neoextractivismo ha redistribuido riqueza a partir de las rentas de la extracción y exportación de materias primas, $\mathrm{y}$ ha fortalecido el rol estatal en el proceso, reproduce las dinámicas propias del extractivismo del siglo XX: de una parte, "una inserción internacional subordinada y funcional a la globalización del capitalismo trasnacional", y de otra, la degradación de la naturaleza y el ejercicio de prácticas autoritarias que atentan contra los derechos de los pueblos y comunidades que habitan las zonas de la extracción (Le Quang y Vercoutère, 2015).

En lo que atañe a la tendencia indígena e indigenista, esta suele ser vinculada con posiciones antiextractivistas, sin embargo, los pueblos indígenas, desde su cosmovisión y prácticas ancestrales, no renuncian a la extracción de recursos naturales, sino que cuestionan el quiebre que aquello pudiese generar en los equilibrios de la vida, asociados a su cosmovisión. Para Viteri (2003), el manejo del bosque bajo el principio de obtener "únicamente aquello que se requiere" es un factor clave del Sumak Kawsay; por tanto, una actividad extractivista a gran escala "constituiría una grave amenaza y un desequilibrio difícil de reparar" para sus objetivos (p. 50).

Esta búsqueda de vinculación del ecologismo y sus propuestas ligadas al Sumak Kawsay y la tradición de los pueblos originarios resuenan en el planteamiento de Martínez (2015), quien sostiene críticamente la existencia de una ecologización de las demandas indígenas en el marco de una producción y venta de nuevas identidades ecológicas a través de un discurso ahistórico de ancestralidad, el cual buscaría resignificar el mito del "noble salvaje" en un "noble salvaje ecológico", otorgándole a los pueblos indígenas un rol de "guardianes de la biodiversidad" con una imagen esencializada.

Por su parte, para el socialismo del Sumak Kawsay y el neodesarrollismo del Buen Vivir, la extracción de materias primas es un instrumento para conseguir recursos que permitan satisfacer las necesidades de la población, y, paradójicamente, avanzar hacia una sociedad posextractivista. El planteamiento sistémico de esta corriente es anticapitalista, por tanto, si bien aspira a un posextractivismo, este no es un fin, sino solamente un elemento para su real objetivo, que es cambiar las estructuras socioeconómicas capitalistas de la sociedad. Bajo esta perspectiva, superar la dependencia de los recursos naturales no significa necesariamente superar el capitalismo y construir la sociedad del Buen Vivir (Le Quang y Vercoutère, 2015).

Para Correa, en el caso ecuatoriano, la extracción petrolera se constituye en una necesidad:

A ustedes no les gusta el petróleo. Les aseguro que a mí tampoco me gusta, pero a todos nos debería disgustar aún más la miseria. Y que nadie se engañe: necesitamos nuestros recursos naturales para superar lo más rápidamente la pobreza, y para un desarrollo soberano. El que les diga lo contrario les está mintiendo (Presidencia República del Ecuador, 15 de agosto de 2013). 
Así, desde el neodesarrollismo del Buen Vivir se mantiene la lógica capitalista, pero se cuestiona y se busca superar el modelo neoliberal hegemónico a través de una mayor distribución de los ingresos generados por las actividades extractivistas.

\section{Conclusiones}

A partir de lo planteado hasta ahora, se proponen algunas conclusiones. En primer lugar, los debates en torno al Buen Vivir se han constituido en un campo donde se desarrolla un permanente proceso de disputa por su significación y apropiación. Cada una de las corrientes en tensión ha tomado y utilizado el significante "Buen Vivir" para simbolizar sus contenidos, propuestas, ideario y construcción discursiva; proceso a través del cual, simultáneamente, buscan llenar tal concepto de un contenido y significado específicos.

En segundo lugar, las tipologías tradicionales establecidas por los autores mencionados en la investigación pueden ser reformuladas y reinterpretadas, tanto en la nomenclatura, así como en la construcción de nuevas categorías, incorporando dos nuevas corrientes provenientes de las tensiones presentes en la vertiente socialista-estatista del Buen Vivir: el "neodesarrollismo del Buen Vivir" y el "socialismo del Sumak Kawsay". Dado que estas dos últimas corrientes han estado mayormente involucradas en la obra del gobierno de Rafael Correa y en la institucionalidad estatal, han conseguido mayores herramientas en la significación y penetración de ese significado en el imaginario de la sociedad ecuatoriana.

En tercer lugar, si bien se reconoce el Buen Vivir como traducción al castellano del Sumak Kawsay, esta versión traducida resulta más permeable al proceso de disputa, constituyéndose en una especie de puerta más abierta a su deconstrucción y reconstrucción, lo que permite preguntarse por el rol de la traducción conceptual en el desarrollo, evolución y utilización de los conceptos, y a partir de ahí, en la relevancia de establecer una asociación académica más estrecha entre los estudios políticos, desde diversas disciplinas, y la traductología. Esta última podría entregar elementos y herramientas valiosas para la comprensión y decodificación de los procesos políticos.

A partir de su incorporación en la Constitución ecuatoriana, en las políticas públicas y en la institucionalidad estatal durante el proceso de Rafael Correa, el Sumak Kawsay y su representación al castellano, el Buen Vivir, adquirieron un mayor reconocimiento público y presencia en los debates políticos del país. Con la llegada de Lenin Moreno al poder, estos debates quedaron al margen del discurso estatal, dado el giro hacia el neoliberalismo producido por el nuevo mandatario. Entretanto, como respuestas a estos cambios económicos, el movimiento indígena ha estado demandando mayor participación en el ámbito político del país, y, en consecuencia, se ha puesto nuevamente la atención en los debates sobre el Sumak Kawsay como alternativa al modelo de desarrollo desde sus propias cosmovisiones, lo que ha ampliado las disputas por el significado del Buen Vivir. 
La distinción que propone el artículo respecto de las corrientes sustantivas e interpretativas del Buen Vivir, y que es el resultado de la revisión del proceso sociopolítico, sociocultural, socioeconómico y socioespacial ecuatoriano, es de utilidad para avanzar hacia el análisis de otros procesos, como es el caso boliviano respecto de su concreción del Suma Qamaña, Vivir Bien, también traducido en reformas constitucionales y de política pública. Tan importante como ello, esta distinción interpretativa que propone este artículo contribuye a la producción teórica y empírica en torno a los debates sobre los pueblos indígenas de América Latina, tanto respecto de aquellas conceptualizaciones elaboradas por ellos mismos, como de otras esbozadas por intelectuales no indígenas, dado que provienen de realidades genuinamente sudamericanas.

\section{Referencias bibliográficas}

Acosta, A. (2015). Amazonía: violencias, resistencias, propuestas. Revista Crítica de Ciencias Sociales, 107, septiembre, 39-62. Recuperado de https://journals.openedition.org/rccs/6004

Asamblea Constituyente de Bolivia. (2009). Constitución Política del Estado de Bolivia. El Alto de La Paz: Asamblea Constituyente.

ACE (2008). Constitución de la República del Ecuador. Montecristi: Asamblea Nacional.

ACE (29 de abril de 2008). Acta N 040. Actas Asamblea Constituyente 2007-2008. Archivo Biblioteca Juan León Mera.

Arauz, A. (2015). Cambio de la matriz productiva. En A. Serrano (coord.), La nueva economía en la nueva constitución del Ecuador (pp. 221-286). Quito: Servicios de Rentas Internas (SRI).

Correa, R. (2010). Ecuador: de Banana Republic a la No República. Buenos Aires: Debate.

Cubillo-Guevara, A. P., Hidalgo-Capitán, A. L. y Domínguez-Goméz, J. A. (2014). El pensamiento sobre el Buen Vivir. Entre el indigenismo, el socialismo y el postdesarrollismo. Revista del CLAD Reforma y Democracia, (60), octubre, 27-58. Recuperado de https://www.redalyc.org/pdf/3575/357533692002.pdf

Cubillo-Guevara, A. P. (2016). Genealogía inmediata de los discursos del Buen Vivir en Ecuador (1992-2016). América Latina Hoy, (74), 125-144. Recuperado de http://www.redalyc.org/pdf/308/30849748007.pdf

Cubillo-Guevara, A. e Hidalgo-Capitán, A. (2015). El sumak kawsay genuino como fenómeno social amazónico ecuatoriano. OBETS. Revista de Ciencias Sociales, 10(2), 301-333. DOI: https://doi.org/10.14198/OBETS2015.10.2.02 
Devés-Valdés, E. (2014). Pensamiento periférico: Asia-África-América Latina-Eurasia y algo más. Una tesis interpretativa global [E-book]. Buenos Aires: Clacso, IdeaUsach. Recuperado de https://library.oapen.org/handle/20.500.12657/29514

Estenssoro, F., y Vásquez, J. P. (2017). Las diferencias norte-sur en el debate ambiental global. El caso de la propuesta del Ecuador: Yasuní-ITT. Universum, 32(2), 63-80. DOI: https://doi.org/10.4067/S0718-23762017000200063

Estenssoro, F. y Vásquez, J. P. (2018). Perspectivas políticas ambientales latinoamericanas. Los casos Chile, Ecuador y Brasil entre Río-92 y Río+20. Revista Estudios Hemisféricos y Polares, 9(3), 1-26. Recuperado de https://www.revistaestudioshemisfericosypolares.cl/ojs/index.php/rehp/article/view/ 31

Fernández, B. S., Pardo, L. y Salamanca, K. (2014). El buen vivir en Ecuador: ¿marketing político o proyecto en disputa? Un diálogo con Alberto Acosta. Íconos. Revista de Ciencias Sociales, (48), enero, 101-117. Recuperado de revistas.flacsoandes.edu.ec/iconos/article/download/1212/1109

Foucault, M. (1996). El orden del discurso. Madrid: Las ediciones de la piqueta.

Harnecker, M. (2011). Ecuador: Una nueva izquierda en busca de la vida en plenitud. Barcelona: El Viejo Topo.

Hidalgo-Capitán, A. y Cubillo-Guevara, A. (2014). Seis debates abiertos sobre el sumak kawsay. Iconos. Revista de Ciencias Sociales, (48), 25-40. DOI: https://doi.org/10.17141/iconos.48.2014.1204

Hidalgo-Capitán, A., Guillén, A. y Deleg, N. (2014). El pensamiento indigenista ecuatoriano sobre el Sumak Kawsay. En A. Hidalgo-Capitán, A. Guillén y N. Deleg (eds.), Antología del pensamiento ecuatoriano sobre Sumak Kawsay (pp. 25-74). Huelva y Cuenca: FIUCUHU.

Hidalgo Flor, F. (2011). Buen vivir, Sumak Kawsay: Aporte contrahegemónico del proceso andino. Utopía y Praxis Latinoamericana, 16(53), 85-94. Recuperado de http://www.redalyc.org/articulo.oa?id=27919220008

Huanacuni, F. (2010). Buen Vivir/Vivir Bien. Filosofia, políticas, estrategias y experiencias regionales andinas. Lima: Coordinadora Andina de Organizaciones Indígenas.

Laclau, E. (2016). La razón populista. México: Fondo de Cultura Económica.

Le Quang, M. y Vercoutère, T. (2015). Ecosocialismo y Buen Vivir. Diálogo entre dos alternativas al capitalismo. Quito: Instituto de Altos Estudios Nacionales.

Martínez, J. (2015). El Paraíso en venta. Desarrollo, etnicidad y ambientalismo en la frontera sur del Yasuní (Amazonía Ecuatoriana). Quito: Abya Yala. 
Ministerio de Planificación del Desarrollo (2016). Plan de Desarrollo Económico y Social. En el marco del Desarrollo Integral para Vivir Bien 2016-2020. La Paz: Ministerio de Planificación del Desarrollo. Estado Plurinacional de Bolivia. Recuperado de http://www.planificacion.gob.bo/pdes/pdes2016-2020.pdf

Mondol, L. (2018). La institucionalización de la "cuestión" indígena desde el Estado costarricense. $\quad$ Ruptura, $8(2), \quad 77-100 . \quad$ Recuperado de https://revistas.uned.ac.cr/index.php/rupturas/article/view/2114

Muñoz, P. (2012). ¿Cómo caminamos al Socialismo del Buen Vivir? Cinco años de Revolución Ciudadana desde el Plan Nacional del Buen Vivir. Corriente Alterna, (01), 19-25. Recuperado de https://repositorio.flacsoandes.edu.ec/bitstream/ 10469/3731/1/REXTN-CA1-05-Mu\%c3\%b1oz.pdf

Presidencia República del Ecuador (30 de agosto de 2013). 29-08-2013 Discurso del presidente Rafael Correa en el Diálogo para el Buen Vivir con las Comunidades y Nacionalidades [Audio en podcast]. Recuperado de: https://www.ivoox.com/29-0813-discurso-del-presidente-rafael-correa-el-audios-mp3_rf_2318326_1.html

Presidencia República del Ecuador (15 de agosto de 2013). Anuncio a la Nación Iniciativa Yasuní ITT. [En línea]. Recuperado de http://www.presidencia.gob.ec/wpcontent/uploads/downloads/2013/08/2013-08-15-AnuncioYasuni.pdf

Querejazu Escobari, A. (2015). Indigeneidad en la política exterior de Bolivia en el gobierno de Evo Morales (2006-2014). Desafios, 27(1), 159-184. Recuperado de http://www.scielo.org.co/pdf/desa/v27n1/v27n1a06.pdf

Ramírez, R. (2010). Socialismo del sumak kawsay o biosocialismo republicano. En Secretaría Nacional de Planificación y Desarrollo (SENPLADES), Los nuevos retos de América Latina. Socialismo y Sumak Kawsay (pp. 55-76). Quito: SENPLADES.

Ramírez, R. (2017). La Gran Transición. En busca de nuevos sentidos comunes. Quito: Ciespal.

Ramos, J. y Vásquez, J. P. (2018). Del petróleo a la bio-inteligencia. Cambio de matriz productiva y economía del conocimiento. Discurso, realidad y proyecciones del caso ecuatoriano. Revista Estudios Avanzados, (29), 105-120. Recuperado de http://www.revistas.usach.cl/ojs/index.php/ideas/article/view/3403

Saussure, F. (2012). Curso de lingüística general. Buenos Aires: Losada.

Secretaría Nacional de Planificación y Desarrollo (SENPLADES) (2009). Plan Nacional para el Buen Vivir 2009-2013. Quito: SENPLADES. Recuperado de https://www.planificacion.gob.ec/wpcontent/uploads/downloads/2012/07/Plan_Nacional_para_el_Buen_Vivir.pdf 
Secretaría Nacional de Planificación y Desarrollo (SENPLADES) (2013). Plan Nacional para el Buen Vivir 2013-2017. Quito: SENPLADES. Recuperado de https://observatorioplanificacion.cepal.org/sites/default/files/plan/files/Ecuador $\% 20$ Plan\%20Nacional\%20del\%20Buen\%20Vivir.pdf

Secretaría Nacional de Planificación y Desarrollo (SENPLADES) (2017). Informe a la Nación 2007-2017. Quito: SENPLADES. Recuperado de http://www.planificacion.gob.ec/wp-content/uploads/downloads/2017/04/Informe-ala-Nacion.pdf

Silva, E. (2003). Mushuk Allpa. La experiencia de los indígenas de Pastaza en el manejo de la selva amazónica. Quito: Instituto Amazanga y Comunidec.

Vanhulst, J. (2015). El laberinto de los discursos del Buen vivir: entre Sumak Kawsay y Socialismo del siglo XXI. Polis. Revista Latinoamericana, (40), 1-25. Recuperado de http://polis.revues.org/10727

Vanhulst, J. y Beling, A. E. (2013). El Buen vivir: Una utopía latinoamericana en el campo discursivo global de la sustentabilidad. Polis, 12(36), 497-522. Recuperado de https://polis.ulagos.cl/index.php/polis/article/view/998/1915

Vásquez, J. P. (2015). La tensión histórica norte-sur global en el debate ambiental. El conflicto en torno a la Iniciativa Yasuni ITT. Revista Estudios Hemisféricos y Polares, 6(1), 1-28. Recuperado de https:/www.revistaestudioshemisfericosypolares.cl/ ojs/index.php/rehp/article/view/122

Vásquez, J. P. y Clavería, L. (2020). A source for greater peripheral sovereignty or a new axis of dependency relations? China and Latin America in the context of the readjustment of forces in the World System: The case of China-Ecuador relations. En E. Mielants y K. Salavei Bardos (eds.), Economic Cycles and Social Movements: Past, Present and Future (pp. 146-154). Nueva York: Routledge.

Viteri, C. (1993). Mundos míticos. Runa. En N. Paymal y C. Sosa (eds.), Mundos amazónicos (pp. 148-150). Quito: Ediciones Sinchi Sacha.

Viteri, C. (2003). Súmak Káusai. Una respuesta viable al desarrollo. (Tesis para obtener el título de Licenciatura en Antropología Aplicada). Universidad Politécnica Salesiana del Ecuador, Quito.

Walsh, C. (2008). Interculturalidad, plurinacionalidad y decolonialidad: las insurgencias político-epistémicas de refundar el Estado. Tabula Rasa, (9), julio-diciembre, 131152. Recuperado de https://www.redalyc.org/pdf/396/39600909.pdf 